Primljen / Received: 6.11.2015. Ispravljen / Corrected: 29.8.2016.

Prihvaćen / Accepted: 30.9.2016. Dostupno online / Available online: 10.3.2017.

\section{Influence of horizontal curvature radius and bent skew angle on seismic response of RC bridges}

Authors:

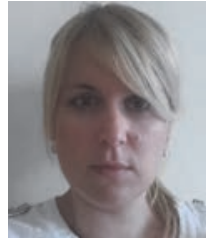

Nina Serdar, MSc. CE

University of Montenegro

Faculty of Civil Engineering

ninas@ac.me

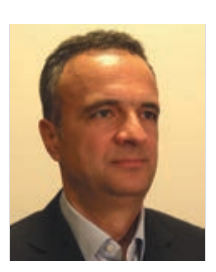

Prof. Srdan Janković, PhD. CE

University of Montenegro

Faculty of Civil Engineering

srdjan@t-com.me

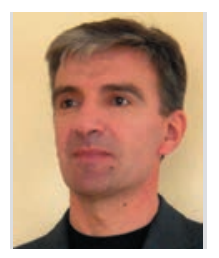

Prof. Mladen Ulićević, PhD. CE

University of Montenegro

Faculty of Civil Engineering

mladen@t-com.me
Nina Serdar, Mladen Ulićević, Srdan Janković

Influence of horizontal curvature radius and bent skew angle on seismic response of $\mathrm{RC}$ bridges

The influence of horizontal curvature radius, bridge bents skew angle, and type of column bents, on the seismic response of bridges is studied in the paper. A total of eighteen frame-system bridges were analysed. More than 2700 nonlinear dynamic analyses were conducted for earthquake records matching a particular location by the magnitude, distance from fault, and foundation soil conditions. The response analysis shows that the system's vulnerability increases with a decrease in curvature radius.

Key words:

curved bridge, skewed bridge, probabilistic response model, intensity rating

Prethodno priopćenje

Nina Serdar, Mladen Uličević, Srdan Janković

Utjecaj horizontalne krivine i kuta kosine stupova na seizmički odziv ab mostova

U radu je analiziran utjecaj radijusa horizontalne krivine, kuta kosine stupova i oblika stupova na seizmički odziv mosta. Ukupno je analizirano 18 mostova okvirnog sustava. Za potresne zapise koji po magnitudi, udaljenosti od rasjeda i uvjetima temeljnog tla odgovaraju određenoj lokaciji, provedeno je više od 2700 nelinearnih dinamičkih analiza. U analizi odziva uočeno je da manji radijus krivine znači i veću oštetljivost sustava.

Ključne riječi:

most u krivini, kosi most, probabilistički model odziva, mjera intenziteta

Vorherige Mitteilung

Nina Serdar, Mladen Ulićević, Srdan Janković

Einfluss von Horizontalkrümmung und Neigungswinkel der Stützen auf die seismische Antwort von Stahlbetonbrücken

In dieser Arbeit werden Einflüsse von Radius der Horizontalkrümmung, Neigungswinkel der Stützen und Stützenform auf die seismische Antwort von Brücken analysiert. Insgesamt wurden 18 Rahmenbrücken untersucht. Für Erdbebenaufzeichnungen, die in Bezug auf Magnitude, Entfernung von der Verwerfung und Baugrundeigenschaften einer bestimmter Lokalität entsprechen, wurden über 2700 nichtlineare dynamische Analysen durchgeführt. Die Antwortanalyse hat gezeigt, dass einem kleineren Radius auch eine größere Beschädigung des Systems entspricht.

Schlüsselwörter:

gekurvte Brücke, schräge Brücke, probabilistisches Antwortmodell, Intensitätsmaß 


\section{Introduction}

Bridges rank among the weakest links in transport network in terms of vulnerability when exposed to earthquake action. According to modern guidelines, bridges should be designed in such a way that their collapse is prevented during strong earthquake motions (earthquakes with a return period of 475 years according to EN 1998-2). If significant damage to a bridge occurs, direct economic losses associated with the cost of reconstruction will certainly be incurred. However, indirect losses caused by loss of bridge function, or by its functioning at a reduced capacity, cannot be neglected. It can be said that predicting seismic response of a bridge structure, and identifying the parameters that affect the vulnerability of a bridge, with the aim of avoiding collapse in case of strong earthquakes, and bringing damage to an acceptable level in case of minor earthquakes, is an important task that has to be properly addressed in research work.

The focus of this paper is on the analysis of seismic response of reinforced curved bridges and bridges with the skewed bridge bent. These structures are highly desirable and sometimes necessary as a means to facilitate traffic transition. They are usually the elements of major freeway interchanges, highway access ramps, overpasses, etc. Experience from past earthquakes has shown that even if curved and skewed bridges are suitable for smooth traffic flow, their response to seismic effects is less predictable and certainly different from the response of straight bridges. In the past, after several strong earthquakes (Northridge (1994), Wenchuan-China (2008), Chile (2010), etc.) such structures have experienced some unexpected types of failure and damage.

Specific behaviour of curved and skewed bridges during seismic excitation is due to their significant coupling between responses in two orthogonal horizontal directions. Columns are subjected to simultaneous bi-axial bending and torsion. An increase in axial, shear and torsional effects can be prompted by torsional vibration modes [1]. Larger in-plane deck rotations induce larger displacements of deck over abutments. In addition to the column-bent failure, the abutment unseating and shear key failure due to large longitudinal and transverse displacements are also important types of failure of skewed and curved bridges. Consequently, they must be further investigated and studied in order to ensure better understanding of their seismic response. After an overview of relevant literature, it can be seen that a very limited number of papers currently deals with seismic response of curved and skewed bridges. In the studies carried out by Tondini and Stojadinović [2], it is highlighted that the decreasing radius of curvature results in a higher bridge vulnerability due to seismic effects. These studies address bridges with a single column bent of circular cross section, and also involve different column heights. The effect of the column bent skew angle was investigated for straight bridges [3, 4]. The results show that an increase in the bridge bent skew angle leads to an increase in the vulnerability of structures, especially in case of straight bridges with seat type abutments. Further research, as indicated in the above references, should include variations of column shapes, impact of skewed angle for curved bridges, analysis of short bridges, and study of collapse and other damage states.

The focus of this paper is on investigation of the effect of three parameters: bridge deck radius in horizontal plane, bridge bent skew angle, and column cross section shape, on the seismic response of a three-span $\mathrm{RC}$ box-girder bridge. The aim is to assess the impact of varied parameters on the behaviour of the structure through a probabilistic approach. This requires establishment of a probabilistic seismic demand model (PSDM), which relates structural response (EDP - Engineering Demand Parameter) to earthquake intensity measure (IM - Intensity Measure). In the literature, this methodology is known as the PBEE methodology [5]. The analysis of seismic response was performed for a total of eighteen bridge prototypes. Three bridge bent skew angles were considered $\left(0^{\circ}, 20^{\circ}\right.$, and $\left.30^{\circ}\right)$ along with two values of horizontal curvature (straight bridge which corresponds to an infinite value of curvature radius, and bridge curvature value of $R=150 \mathrm{~m}$ - which is larger than the prescribed minimum value on roads with the relevant design speed of up to $60 \mathrm{~km} / \mathrm{h}$ ) and three types of the bridge column cross-section shape. Bridges are classified into three types $A$, $B$, and $C$ according to the shape of the column cross-section: hollow box column, double column bent with circular crosssection, and rectangular column cross-section, respectively.

\section{Description of bridge prototypes}

The investigated bridge prototype is a three-span frame bridge with individual spans measuring $32 \mathrm{~m}, 40 \mathrm{~m}$, and $32 \mathrm{~m}$ (see Figure 1). For a curved bridge, span length refers to an appropriate circular arch length. The superstructure is a one cell box girder measuring $10 \mathrm{~m}$ in total width and $2.5 \mathrm{~m}$ in height. The column height, a)

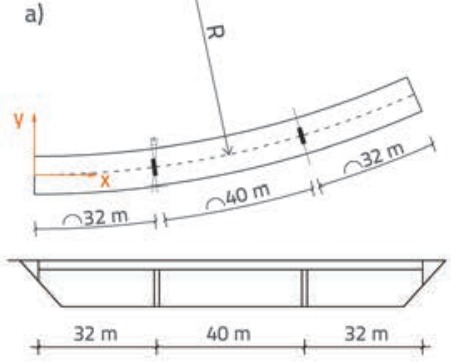

b)

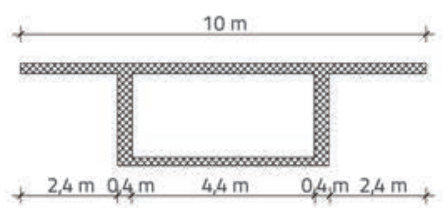

c)

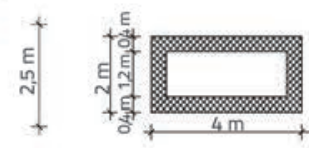

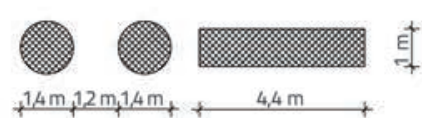

Figure 1. a) Plan view and longitudinal configuration of bridge; b) bridge deck cross-section; c) column cross-section for bridge types A; B and C 
measured from foundations to the bridge deck, is $10 \mathrm{~m}$. Columns are fully restrained in foundations. The bridge deck is rigidly connected to columns. The column crosssection is a hollow box, double bent either with circular piers or with piers of rectangular cross-section, depending on the type of bridge ( $\mathrm{A}, \mathrm{B}$ or $\mathrm{C}$ ). Bridge deck is supported over seat-type abutments with four elastomeric bearings, movable in longitudinal direction. The concrete class is assumed to be $C 30 / 37$, and the quality of reinforcing steel is $\mathrm{B} 500 \mathrm{~B}$.

Bridges were designed in accordance with European standards EN 1991-2

[6] EN 1992-1-1 [7] and EN 1998-2 [8]. The three-dimensional span model with line elements of appropriate geometric characteristics was used for linear analysis, which was conducted using the software package SAP 2000 v.14. [9]. Geometric properties of an uncracked cross section are taken for modelling bridge deck, while the effective flexural stiffness of columns is estimated according to Annex C EN 1998-2 [8]. Each span is modelled by ten straight elements to an approximated horizontal curvature of the bridge. Columns are fully fixed in the base and all movements and rotations are restrained. Deck movements at abutments in the vertical and transverse directions are restrained, and rotation around the axis perpendicular to the longitudinal plane of the bridge deck is allowed.

Seismic analysis was performed using the multimodal spectral analysis. First twelve vibration tones were taken into account, which was sufficient for the sum of effective modal masses to be higher than $90 \%$ of the total mass. The horizontal seismic action was specified through the design response spectrum for $\mathrm{B}$ category soil and the design ground acceleration of ag = $0.4 \mathrm{~g}$. Ductile behaviour of the structure and the corresponding behaviour factor q were adopted. The corresponding values are given in Table 1. The vertical seismic load was not taken into account in column design. Reinforcement percentages in columns are given in Table 1.

\section{Non-linear modelling of bridge}

Main aspects of bridge modelling for the purpose of conducting non-linear dynamic analysis (NDA) are presented in this section.
Table 1. Geometric characteristics and bridge description

\begin{tabular}{|c|c|}
\hline Structural bearing system & 3 span frame, with central span of 40 m, and with 32 m end spans \\
\hline Bent skew angle & $0^{\circ}, 20^{\circ}, 30^{\circ}$ \\
\hline $\begin{array}{l}\text { Radius of curvature in } \\
\text { horizontal plane }\end{array}$ & Straight bridge: $R=$ inf; Curved bridge: $R=150 \mathrm{~m}$ \\
\hline $\begin{array}{l}\text { Deck cross-section geometric } \\
\text { characteristic }\end{array}$ & $\begin{array}{l}\mathrm{EA}=1,97 \cdot 10^{8} \mathrm{kN} ; \\
\mathrm{El}_{\mathrm{x}}=1,8 \cdot 10^{8} \mathrm{kNm}^{2} ; \mathrm{El}_{\mathrm{y}}=1,3 \cdot 10^{9} \mathrm{kNm}^{2} ; \mathrm{GJ}=1.55 \cdot 10^{8} \mathrm{kNm}^{2}\end{array}$ \\
\hline Shape and size of columns & $\begin{array}{l}\text { Type A: Hollow box b x } \mathrm{d}=2 \times 4 \mathrm{~m} ; \mathrm{d}_{\text {zida }}=0.4 \mathrm{~m} \\
\text { Type B: Double column bent circular section diameter of } 1.4 \mathrm{~m} \\
\text { Type C: Rectangular wall type column } 1 \times 4.4 \mathrm{~m}\end{array}$ \\
\hline Behavior factor q & $\begin{array}{l}\text { Type A: } q_{\text {longitudinal }}=q_{\text {transversal }}=3.2 \\
\text { Type B: } q_{\text {longitudinal }}=q_{\text {transversal }}=3.5 \\
\text { Type C: } q_{\text {longitudinal }}=3,5 ; q_{\text {transversal }}=3\end{array}$ \\
\hline $\begin{array}{l}\text { Longitudinal reinforcement in } \\
\text { columns (number of bars x bar } \\
\text { diameter } \phi \text { ) }\end{array}$ & $\begin{array}{l}\text { Type A: } \rho_{\mathrm{L}}=2 \%(2 \times 2 \times 14 \phi 28 \text { along width and } 2 \times 2 \times 21 \phi 28 \\
\text { along depth) } \\
\text { Type B: } \rho_{\mathrm{L}}=2.7 \%(40 \phi 36) \\
\text { Type C: } \rho_{\mathrm{L}}=3.3 \%(2 \times 24 \phi 36 \text { along width and } 2 \times 48 \phi 36 \\
\quad \text { along depth) }\end{array}$ \\
\hline $\begin{array}{l}\text { Transverse reinforcement } \\
\text { in columns (bar diameter } \phi / \\
\text { longitudinal space) }\end{array}$ & $\begin{array}{l}\text { Type A: } \rho_{\mathrm{Tx}}=0.4 \% \text { (longitudinally); } \rho_{\mathrm{Ty}}=0.55 \% \text { (transversely) } \\
(\phi 10 / 15) \\
\text { Type B: } \rho_{\mathrm{T}}=1,21 \%(\phi 20 / 8) \\
\text { Type C: } \rho_{\mathrm{Tx}=} 1.5 \% \text { (longitudinally); } \rho_{\mathrm{Ty}}=0.7 \% \text { (transversely) } \\
\quad(\phi 16 / 11.5)\end{array}$ \\
\hline
\end{tabular}

Table 2. Characteristic of confined and unconfined concrete and reinforcement

\begin{tabular}{|c|c|}
\hline \multicolumn{2}{|l|}{ Confined concrete } \\
\hline $\begin{array}{l}\mathrm{f}_{\mathrm{cm}, \mathrm{c}}-\text { maximum compressive strength based on mean value for } \\
\text { compressive strength } \mathrm{f}_{\mathrm{cm}{ }^{\prime}} \text { according to [7] (typeA-typeB-typeC) }\end{array}$ & $57-57-54 \mathrm{MPa}$ \\
\hline$\varepsilon_{\mathrm{c} 1, \mathrm{c}}$ - strain at $\mathrm{f}_{\mathrm{cm}, \mathrm{c}}$ (typeA-typeB-typec) & $0.008-0.008-0.007$ \\
\hline$\varepsilon_{\mathrm{cu}, \mathrm{c}}-$ maximum strain & 0.033 \\
\hline Vlačna čvrstoća & 0 \\
\hline \multicolumn{2}{|l|}{ Unconfined concrete } \\
\hline $\mathrm{f}_{\mathrm{cm}}$ - mean value for compressive strength & $38 \mathrm{MPa}$ \\
\hline$\varepsilon_{\mathrm{c} 1}-$ strain at $\mathrm{f}_{\mathrm{cm}}$ & 0.0022 \\
\hline$\varepsilon_{\mathrm{cu}, 1}-$ maximum strain & $0 ., 0035$ \\
\hline Tensile strength & 0 \\
\hline Elasticity modulus & $33 \mathrm{GPa}$ \\
\hline \multicolumn{2}{|l|}{ Reinforcing steel } \\
\hline$f_{y m}$ - mean value for yield strength & $575 \mathrm{MPa}$ \\
\hline Elasticity modulus & $200 \mathrm{GPa}$ \\
\hline
\end{tabular}

Many authors addressed the issue of structure and material modelling, and so recommendations given in the corresponding literature [10] will be applied in the present study. The bridge modelling and analysis were conducted in the program for nonlinear analysis SeismoStruct version 7.0.3 [11]. The bridge deck was modelled using linear elements located at the centre of gravity of deck cross-sections. Elastic frame elements were used because non-linear behaviour is not expected to occur in deck during earthquake action. Geometric properties of an uncracked deck cross-section were used for elastic elements, according to relevant recommendations given in European 
standards [8]. Each span is modelled by eight straight elements to an approximated bridge curvature in horizontal plane.

Mander's uniaxial nonlinear concrete model was used for the confined concrete modelling [12]. The behaviour under cyclic loading was modelled according to the suggestion given in [13]. The properties of steel were taken according to [8]. Material characteristic are given in Table 2 .

As substantially plastic behaviour is expected in columns, a column has been modelled as a single inelastic element starting at the foundation and ending at the bottom of the deck. The distributed nonlinearity along the length of the column was assumed. The cross-section was divided into the material of the concrete core - confined concrete, concrete of the protective layer - unconfined concrete, and reinforcing steel. At the level of cross section, the stress-strain state was obtained by integrating non-linear uniaxial stress-strain responses of individual "fibres" into which the cross-section was divided. The number of crosssections in which the integration was conducted was five. An elastic rigid element was used to model the column to deck connection. The cap-beam for two column bent was modelled as an elastic frame element with an increased torsion stiffness because of the influence of high flexural superstructure stiffness. A simplified model was used for abutment modelling. Abutments were modelled as infinitely rigid linear elements without weight, using width of the span structure. The weight of the abutments was neglected because it is assumed that it has no greater impact on the overall response of longer bridges. Zero-length link elements were modelled at each end of the element, in vertical and horizontal directions, so as to represent soil characteristics and embankment fill characteristics. Zerolength link elements were assigned in longitudinal direction, with no tensile stiffness, to represent the back-wall and embankment fill response where passive pressure is activated after closing the gap. The link element stiffness $\left(\mathrm{K}_{\mathrm{abt}, \mathrm{L}}\right)$ was calculated according to Caltrans recommendations [14], and it depends on the initial soil stiffness $\left(K_{i}\right)$, the height of the abutment (h), and the width of the abutment (w), using the expression in Equation (1). As two link elements are assigned at each end, the associated stiffness for one element is equal to one half of the above calculated value.

$K_{a b t, L}=K_{i} \cdot w \cdot\left(\frac{h}{1.7}\right)$

An elastic ideal-plastic behaviour was adopted for the link element forcedisplacement diagram in longitudinal direction [14].
In transverse direction, zero-length link elements are also modelled to represent soil stiffness. These elements represent resistance of the embankment fill and wing wall. For simplicity reasons, contribution of stiffness of the protecting wall and bearings was ignored. The transverse stiffness is obtained by multiplying the stiffness in longitudinal direction, shown in equation (1), the wing wall efficiency coefficient $\left(C_{L}=2 / 3\right)$, participation factor $\left(C_{w}=4 / 3\right)$, and the aspect ratio of wing wall and back wall width [15]. As two link elements are assigned in transverse direction, one at each end, the associated stiffness for one element is equal to a half of the above calculated value. In vertical direction, the stiffness that matches soil stiffness under the foundation was assigned to elastic link elements. The effect of the vertical embankment stiffness and vertical stiffness of elastomeric bearings is not accounted for.

Modal damping is considered with the value of $5 \%$.

\section{Modal analysis results}

Modal analysis was conducted for all investigated bridges. First twelve vibration periods and mode shapes were calculated. The first three vibration periods for bridges type $A, B$, and $C$ are shown in Table 3. Short columns, ten meters in height (aspect ratio of span to column height amounts to $\mathrm{L} / \mathrm{H}=4$ ), resulted in a rather stiff structure with the relatively low vibration mode periods. For all bridge types, the fundamental vibration mode

Table 3. First three periods of vibration for bridges A, B and C

\begin{tabular}{|c|c|c|c|c|c|c|}
\hline \multirow[b]{2}{*}{$\begin{array}{l}\text { Bridge } \\
\text { type }\end{array}$} & \multirow[b]{2}{*}{$\begin{array}{c}\text { Curvature } \\
\text { radius } \\
\text { [m] }\end{array}$} & \multirow[b]{2}{*}{$\begin{array}{c}\text { Bent skew } \\
\text { angle }\end{array}$} & \multicolumn{4}{|c|}{ Periods of vibrations $\mathrm{T}$ [s] } \\
\hline & & & $\begin{array}{c}1^{\text {st }} \text { mode } \\
\text { (transverse } \\
\text { direction) }\end{array}$ & $\begin{array}{c}2^{\text {nd }} \text { mode } \\
\text { (longitudinal } \\
\text { direction) }\end{array}$ & $3^{\text {rd }} \mathrm{m}$ & \\
\hline \multirow{6}{*}{ A } & \multirow{3}{*}{$\infty$} & $0^{\circ}$ & 0.596 & 0.327 & 0.230 & \multirow{6}{*}{ 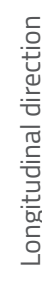 } \\
\hline & & $20^{\circ}$ & 0.600 & 0.326 & 0.235 & \\
\hline & & $30^{\circ}$ & 0.606 & 0.325 & 0.241 & \\
\hline & \multirow{3}{*}{150} & $0^{\circ}$ & 0.596 & 0.328 & 0.231 & \\
\hline & & $20^{\circ}$ & 0.604 & 0.327 & 0.239 & \\
\hline & & $30^{\circ}$ & 0.609 & 0.326 & 0.242 & \\
\hline \multirow{6}{*}{ B } & \multirow{3}{*}{$\infty$} & $0^{\circ}$ & 0.867 & 0.749 & 0.431 & \multirow{6}{*}{ 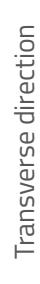 } \\
\hline & & $20^{\circ}$ & 0.882 & 0.729 & 0.433 & \\
\hline & & $30^{\circ}$ & 0.892 & 0.710 & 0.435 & \\
\hline & \multirow{3}{*}{150} & $0^{\circ}$ & 0.849 & 0.731 & 0.438 & \\
\hline & & $20^{\circ}$ & 0.867 & 0.706 & 0.437 & \\
\hline & & $30^{\circ}$ & 0.877 & 0.696 & 0.438 & \\
\hline \multirow{6}{*}{ C } & \multirow{3}{*}{$\infty$} & $0^{\circ}$ & 0.608 & 0.546 & 0.319 & \multirow{6}{*}{ 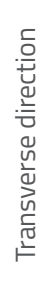 } \\
\hline & & $20^{\circ}$ & 0.644 & 0.511 & 0.313 & \\
\hline & & $30^{\circ}$ & 0672 & 0.486 & 0.306 & \\
\hline & \multirow{3}{*}{150} & $0^{\circ}$ & 0.608 & 0.537 & 0.323 & \\
\hline & & $20^{\circ}$ & 0.658 & 0.498 & 0.315 & \\
\hline & & $30^{\circ}$ & 0.678 & 0.486 & 0.311 & \\
\hline
\end{tabular}


was in transverse direction, with mode periods ranging from 0.6 to $0.9 \mathrm{~s}$

Vibration periods shown in Table 3 are periods with the highest magnitude in a particular direction. Effective modal mass participation factors are not presented in this paper, and so it can be concluded that the influence of higher vibration modes is significant for bridges type $A$ and $C$ (those with relatively stiff piers compared to the deck). Bridges type $A$ and $C$ do not dominantly oscillate in the first mode shape.

It was found that the period of vibration in longitudinal direction decreases with an increase in the bridge bent skew angle. This was found for both curved and straight bridges. A significant decrease in periods occurred in bridge types $B$ and $C$, while this effect was less pronounced in bridge type A. Also, vibration periods in transverse direction increase with an increase in skewness.

A decrease in the radius of curvature of the bridge type $B$ led to reduction in vibration periods in the transverse and longitudinal directions, as well as to reduction in vibration periods of the bridge type C in longitudinal direction, for all skew angles investigated. The bridge type $A$ has relatively stiff piers in both directions compared to the deck, as well as the bridge type $C$ in transverse direction. This caused a decrease in the bridge deck dominance over dynamic response of the bridge, and pointed out the influence of higher vibration modes and stiffness of the columns. Thus, reduction in the radius of curvature is not reflected in the same way in the change of fundamental vibration period for bridge $A$ and bridge $C$ in transverse direction, compared to the effect of the radius of curvature reduction on fundamental periods of the bridge type $B$.

Modal mass participation factors for significant modes of vibrations, vibration mode shapes and modal displacements will not be presented in this paper, due to space limitations. However, these values were analysed and it was concluded that the coupling between modal responses in longitudinal and transversal directions increases with an increase in the bridge bent skewness. Transverse vibration mode shapes do not quite correspond to the transverse horizontal motion, but they have a significant component of longitudinal displacement. The most pronounced coupling of longitudinal and transverse vibration modes was found in the bridge type $B$ (bridges with double circular columns) compared to the other two bridge types. For curved bridges, there was a noticeable increase in the contribution of torsion mode.

\section{Selection of ground motion and earthquake intensity measures}

Selection of earthquake records for the nonlinear dynamic analysis is carried out according to the pre-defined earthquake scenario and soil conditions. The values of magnitude $\mathrm{M}=7$ and distance from fault $R_{L}=20 \mathrm{~km}$, are the values that are considered for the location. Near fault effects are not considered in this paper. Soil site conditions coincide with the ground category B, as it is defined in European standards EN 1998-1.
The most accurate way to assess a structure's response to earthquake action would be to choose a large number of earthquakes with a consistent earthquake scenario, and to use them unscaled as an input for the non-linear dynamic analysis. This approach is not practically possible. Namely, the number of records with the magnitude, distance and soil conditions that are consistent with the earthquake scenario is insufficient. Therefore, search conditions are loose, which resulted in the selection of a larger number of earthquake records.

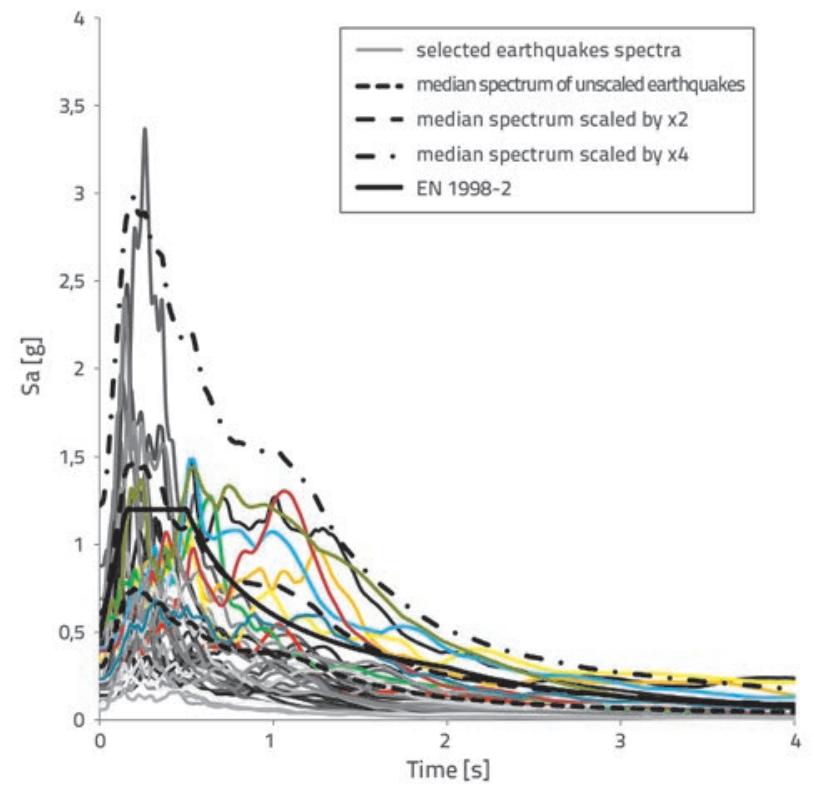

Figure 2. Resulting spectra for scaled and unscaled records

This means that earthquakes that satisfy the following conditions: $6.2<\mathrm{M}<7.6,15 \mathrm{~km}<\mathrm{R}_{\mathrm{L}}<30 \mathrm{~km}$ and $360 \mathrm{~m} / \mathrm{s}<\mathrm{v}_{\mathrm{s}, 30}<800 \mathrm{~m} /$ $\mathrm{s}$ (where $\mathrm{v}_{\mathrm{s}, 30}$ is the speed of shear waves in the ground down to the depth of $30 \mathrm{~m}$ ) were extracted from the available earthquake databases (European Strong Motion Database and PEER Strong Motion Database). The search resulted in the selection of a total of 38 records (one record consists of a pair of orthogonal horizontal components of ground motion acceleration records). Earthquake records were scaled only in amplitude without changing their frequency content. The records were scaled up by factors of 1 , 2,4 , and 8 , which resulted in two hundred and fifty earthquake records for input in NDA. Both horizontal components of motion were applied to the structure at the same time, one in the global $X$ direction, and the other in the global $Y$ direction. Scaling was necessary to ensure non-linear behaviour of the structure. Only those structural responses obtained from NDA, in which ductility displacements did not exceed 4, were considered in further analysis. Several authors consider that this ductility displacement value represents the limit between the limit state corresponding to a major damage in columns and the collapse limit state [16, 17]. In other words, this paper investigates only the no-collapse cases. The resulting acceleration spectra for selected earthquake records, obtained as a vector sum of two horizontal components 
of acceleration spectra, are given in Figure 2. The resulting acceleration spectrum, representative of seismic action on bridges, is also applied in European regulations EN 1998-2.

Selection of the earthquake intensity measure - IM (IM-Intensity Measure), which effectively quantifies seismic action, is a very sensitive issue in the seismic analysis of structures. An efficient intensity measure is a measure that has a small dispersion (Equation (3)), in correlation with the considered structural response. Measures such as PGA (Peak Ground Acceleration) or PGD (Peak Ground Displacement) have been widely represented in previous studies. The PGA is a measure that is still predominantly represented in seismic regulations. Subsequent studies have shown that there is no universal intensity measure that would be suitable for all types of structures, and that the measures such as the spectral acceleration, velocity, and displacement can be considered as relatively appropriate from the aspect of efficiency [18].

Table 4. Analysed seismic intensity measures

\begin{tabular}{|c|c|}
\hline Measure (IMs) & Description \\
\hline trans_PGA & $\begin{array}{l}\text { Peak ground acceleration from the component } \\
\text { applied in transverse direction }\end{array}$ \\
\hline trans_PGV & $\begin{array}{l}\text { Peak ground velocity from the component applied } \\
\text { in transverse direction }\end{array}$ \\
\hline trans_Sa $\left(\mathrm{T}_{1}\right)$ & $\begin{array}{l}\text { Spectral acceleration for period of fundamental } \\
\text { vibration mode of the component applied in } \\
\text { transverse direction }\end{array}$ \\
\hline rez_PGA & $\begin{array}{l}\text { Resultant peak ground acceleration calculated } \\
\text { from two horizontal components }\end{array}$ \\
\hline rez_PGV & $\begin{array}{l}\text { Resultant peak ground velocity calculated from } \\
\text { two horizontal components }\end{array}$ \\
\hline rez_Sa $\left(T_{1}\right)$ & $\begin{array}{l}\text { Spectral acceleration for period of fund. vib. mode } \\
\text { of the resultant spectrum }\end{array}$ \\
\hline rez_Sv( $\left.T_{1}\right)$ & $\begin{array}{l}\text { Spectral velocity for period of fund. vib. mode of } \\
\text { the resultant spectrum }\end{array}$ \\
\hline rez_Sd $\left(T_{1}\right)$ & $\begin{array}{l}\text { Spectral displacement for period of fund. vib. mode } \\
\text { of the resultant spectrum }\end{array}$ \\
\hline rez_Cordova & $\begin{array}{l}\text { Intensity measure [20] calculated from resultant } \\
\text { spectra: } \\
S_{a}=S_{a}\left(T_{1}\right) \sqrt{\frac{S_{a}\left(2 T_{1}\right)}{S_{a}\left(T_{1}\right)}}\end{array}$ \\
\hline
\end{tabular}

From the list of intensity measures recommended in the literature [19], this paper presents results for those measures that have proven to be effective, but also for the measures that are in use in common practice, such as the PGA. Furthermore, in addition to measures obtained from the individual horizontal components of motion (trans prefix before the name of measure), the measures arising from the resultant acceleration, velocity and displacement records and the resultant spectra were also used in this study (prefix rez before the name of the measures). The resultant record/spectrum was obtained as the vector sum of two records / spectra of horizontal components. Other authors [4] investigated resultant measures such as the PGA and PGV for skewed bridges, and concluded that the resultant PGV has proven to be a suitable measure. This approach (consideration of resulting measures) is extended in this paper to all spectral measures as well as to measures that directly depend on spectral measures (rez_Sa (T1), rez_Sv (T1), rez_Cordova etc.). The final list of analysed intensity measures is given in Table 4.

\section{Analysis of seismic response of structures}

The analysis of seismic response of curved and skewed bridges is presented in this section. The aim was to identify the effect of the radius of horizontal curvature, angle of skewness, and column shape, on seismic response of the structure. With this purpose, non-linear dynamic analyses (NDA) were conducted on bridges described in section 2. Maximum relative displacement of top of the column divided by column height (CDR - Column Drift Ratio) was recorded in each NDA and selected for the engineering demand parameter (EDP). The CDR in transverse direction (global $Y$ direction) and the resulting CDR derived from the transversal and longitudinal CDR (global $Y$ and $X$ directions) are considered. The results obtained by analysis of the seismic IMs efficiency in correlation with EDP are presented and discussed in this section. Derived EDP-IM curves are based only on pairs of EDP and IM where the displacement ductility does not exceed the value of 4 .

The spectra of those earthquakes that caused structural ductility displacements greater than 4 are plotted in colour line in Figure 2. It can be noted that these spectra have higher spectral acceleration values on wider range of periods, which underlines the importance of the so-called softening of the structure and extension of vibration periods when the structure enters nonlinear behaviour due to seismic action.

In the probabilistic seismic analysis it is assumed that structural response (EDP) is log-normally distributed when conditioned on intensity measure (IM) I and that this relationship can be written as in equation (3):

$\ln (E P D)=a+b \ln (/ M)$

Coefficients $a$ and $b$, as well as dispersion of the results $\sigma_{E D P \mid I M}$ are obtained from the regression analysis. Dispersion is calculated as the square root of the sum of squares of errors divided by the number of samples (results) minus one. The dispersion value for all bridges and analysed intensity measures are given in Table 5. The measures calculated from records/spectra in transverse direction are correlated to structural response in transverse direction, and the resultant measures are correlated to resultant response.

From the results shown, it can be concluded that among the measures that do not depend on structural characteristics the intensity measures trans_PGV stand out as efficient by the criteria of dispersion, with values ranging from 0.315 to 0.418 . The biggest dispersion for this IM occurs in the bridge type $B$ (two-column bent). It is precisely for this bridge type $B$ that the intensity measure rez PGV, with dispersion values ranging from 0.317 to 0.347 , shows a higher efficiency compared to trans_PGV. Intensity measures related 
Table 5. Dispersion of results of investigated intensity measures

\begin{tabular}{|c|c|c|c|c|c|c|c|c|c|c|c|}
\hline \multirow{3}{*}{$\begin{array}{c}\text { Bridge } \\
\text { type }\end{array}$} & \multirow{3}{*}{$\begin{array}{c}\mathbf{R} \\
{[\mathrm{m}]}\end{array}$} & \multirow{3}{*}{$\alpha$} & \multicolumn{9}{|c|}{ Intensity measure } \\
\hline & & & Trans_PGA & Trans_PGV & Trans_Sa(T1) & rez_PGA & rez_PGV & rez_Sa(T1) & rez_Sv(T1) & rez_Sd(T1) & rez_cord \\
\hline & & & \multicolumn{9}{|c|}{$\sigma_{E D P \| M}$} \\
\hline \multirow{6}{*}{ A } & \multirow{3}{*}{$\infty$} & $0^{\circ}$ & 0.556 & 0.391 & 0.350 & 0.485 & 0.403 & 0.307 & 0.280 & 0.307 & 0.344 \\
\hline & & $20^{\circ}$ & 0.527 & 0.348 & 0.315 & 0.482 & 0.389 & 0.284 & 0.272 & 0.284 & 0.318 \\
\hline & & $30^{\circ}$ & 0.495 & 0.328 & 0.323 & 0.495 & 0.397 & 0.306 & 0.297 & 0.306 & 0.319 \\
\hline & \multirow{3}{*}{150} & $0^{\circ}$ & 0.534 & 0.344 & 0.371 & 0.459 & 0.357 & 0.295 & 0.270 & 0.296 & 0.325 \\
\hline & & $20^{\circ}$ & 0.496 & 0.341 & 0.325 & 0.487 & 0.327 & 0.279 & 0.255 & 0.279 & 0.306 \\
\hline & & $30^{\circ}$ & 0.506 & 0.364 & 0.36 & 0.467 & 0.385 & 0.269 & 0.247 & 0.270 & 0.285 \\
\hline \multirow{6}{*}{ B } & \multirow{3}{*}{$\infty$} & $0^{\circ}$ & 0.579 & 0.418 & 0.412 & 0.51 & 0.321 & 0.263 & 0.276 & 0.263 & 0.247 \\
\hline & & $20^{\circ}$ & 0.589 & 0.425 & 0.411 & 0.569 & 0.318 & 0.262 & 0.279 & 0.261 & 0.254 \\
\hline & & $30^{\circ}$ & 0.578 & 0.396 & 0.380 & 0.565 & 0.317 & 0.269 & 0.281 & 0.268 & 0.251 \\
\hline & \multirow{3}{*}{150} & $0^{\circ}$ & 0.573 & 0.408 & 0.410 & 0.577 & 0.347 & 0.266 & 0.278 & 0.266 & 0.261 \\
\hline & & $20^{\circ}$ & 0.547 & 0.357 & 0.391 & 0.53 & 0.342 & 0.274 & 0.295 & 0.274 & 0.254 \\
\hline & & $30^{\circ}$ & 0.537 & 0.366 & 0.374 & 0.575 & 0.311 & 0.265 & 0.283 & 0.265 & 0.248 \\
\hline \multirow{6}{*}{ C } & \multirow{3}{*}{$\infty$} & $0^{\circ}$ & 0.487 & 0.358 & 0.336 & 0.517 & 0.409 & 0.282 & 0.305 & 0.288 & 0.261 \\
\hline & & $20^{\circ}$ & 0.548 & 0.373 & 0.374 & 0.53 & 0.444 & 0.374 & 0.331 & 0.302 & 0.280 \\
\hline & & $30^{\circ}$ & 0.543 & 0.347 & 0.354 & 0.57 & 0.474 & 0.331 & 0.338 & 0.332 & 0.282 \\
\hline & \multirow{3}{*}{150} & $0^{\circ}$ & 0.504 & 0.347 & 0.321 & 0.534 & 0.415 & 0.308 & 0.322 & 0.308 & 0.286 \\
\hline & & $20^{\circ}$ & 0.427 & 0.315 & 0.378 & 0.546 & 0.444 & 0.31 & 0.314 & 0.310 & 0.249 \\
\hline & & $30^{\circ}$ & 0.501 & 0.34 & 0.391 & 0.615 & 0.477 & 0.358 & 0.365 & 0.358 & 0.293 \\
\hline
\end{tabular}

to acceleration are characterized by a considerable dissipation, which is expected considerig the value of the fundamental vibration period. These results are consistent with research results of other authors [21] obtained for different types of structures that had higher values of fundamental vibration periods.

From the measures that depend on structural characteristics, for example vibration period, the intensity measure proposed by Cordova, calculated from the resulting acceleration spectrum, showed the smallest dispersion, ranging from 0.247 to 0.344 . This intensity measure stands out especially for structures B and C, where the so-called structure "softening", due to the effect of strong earthquakes, and extension of vibration period, have a significant effect on structural response. Beside this measure, the measures like rez_Sa $\left(T_{1}\right)$, rez_Sv $\left(T_{1}\right)$ and rez_Sd $\left(T_{1}\right)$ showed a relatively good and mutually correspondent efficiency. It should be noted that all resulting spectral measures correlated to the resulting CDR constitute a better probabilistic seismic demand model compared to the probabilistic seismic demand model established by pairs of IM-EDP related only to transverse components. Even if the measure proposed by Cordova, calculated from the resultant spectrum, stands out as most efficient, the measure rez_Sd $\left(T_{1}\right)$ was selected as it constitutes the probabilistic seismic response model (PSDM) by the criterion of practicality in calculation. The results shown support the conclusion that the resulting spectral displacement is a good choice and that it has a satisfactory efficiency, with the dispersion ranging from 0.261 to 0.358 , given the fact that supreme intensity measures have the dispersion ranging from 0.2 to 0.3 [10].
It has been observed in the probabilistic seismic demand model that the regression coefficient $a$ increases with the decrease in the radius of curvature (Figure 3). No clear pattern of influence of curvature on the dispersion of results has been detected. An increase in the skew angle leads to an increase in the regression coefficient $a$ only for bridge types A and C (single column). This trend has not been observed for bridges with the double column bent (type $B$ ), with significant coupling of responses in the longitudinal and transverse directions.

The variation of the resultant column drift ratio (rez_CDR) as a function of the resultant spectral displacement (rez_Sd $\left(T_{1}\right)$ ) is given in Figure 3 for all investigated bridge types. One of the trends identified in the PSDMs is that, in case of straight bridges A and C, the response of the structure shows the trend of increase with respect to an increase in skewness. The difference is that regression lines are parallel for the bridge type A (Figure 3.a), while the bridge type $C$ exhibits a more complex behaviour. Regression lines intersect for type $C$ bridges, suggesting that an increase in response is more pronounced as the intensity of ground motion increases (Figure 3.e). Regression lines also intersect for straight type B bridges, but the observed trend is such that for higher seismic intensity structural responses equalize between themselves, and for lower seismic intensity the smaller the skew angle the higher the value of response. Apparently, in case of type B structures, the coupling of response becomes more pronounced for higher seismic intensity, and affects the CDR more seriously.

Furthermore, it was observed that curved bridges of type $B$, unlike straight bridges of type $B$, have regression lines that are parallel and almost coincident, suggesting that this curved double-column 
a)
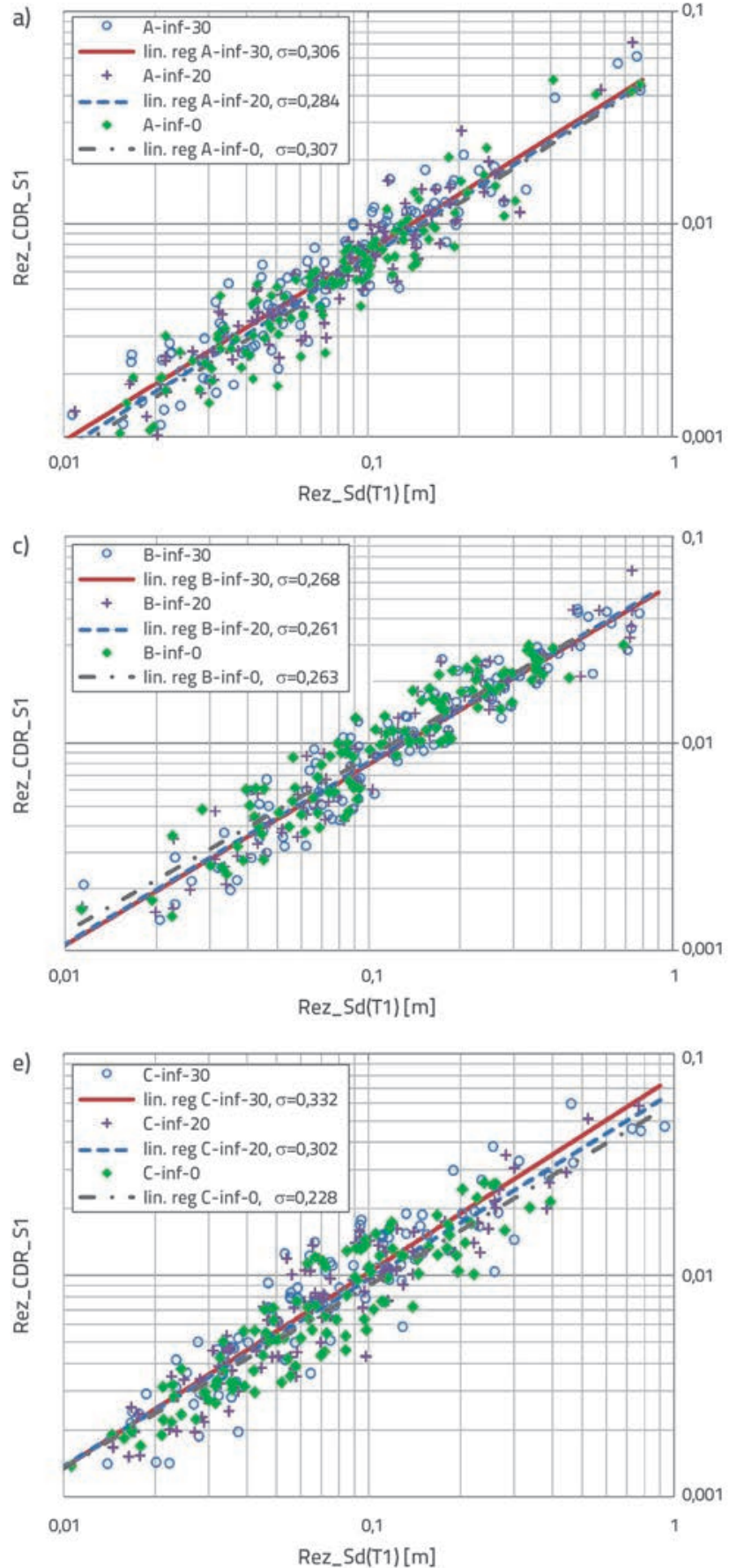

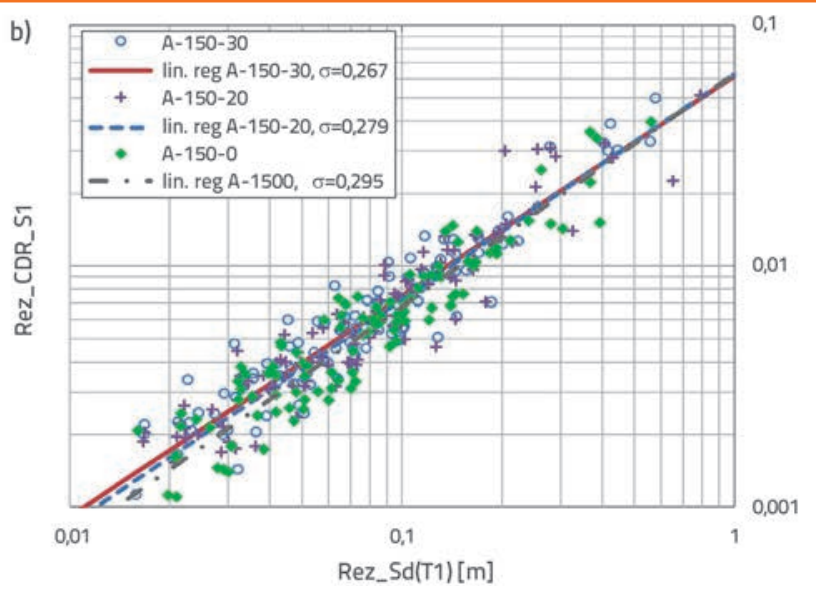

d)

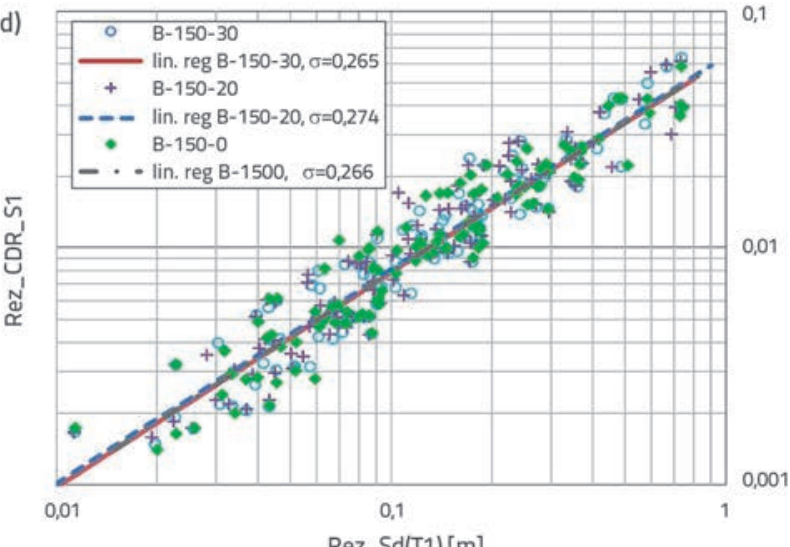

Rez_Sd(T1)[m]

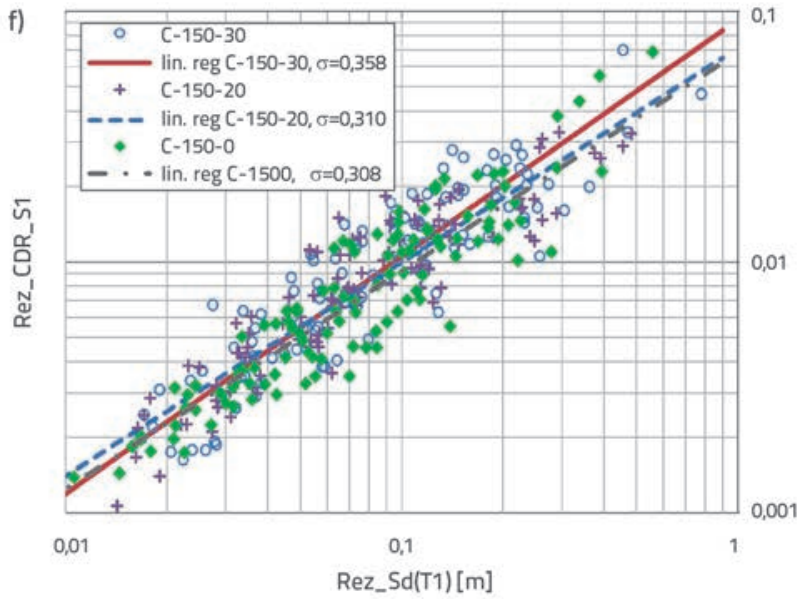

Figure 3. EDP-IM for: a) straight bridge $A$; b) curved bridge $A$; $C$ ) straight bridge $B$; d) curved bridge $B$; e) straight bridge $C$ f) curved bridge $C$

bent bridge is at minimum sensitivity with regard to variation of skew angle (Figure 3.d).

Curved bridges $A$ and $C$ exhibit similar behaviour as their straight counterparts: as the value of seismic intensity gets higher, an increase in skewness leads to higher structural response values (Figure 3.b and 3.f). Finally, a decrease in deck curvature radius (from the infinitive value $(R=$ inf) corresponding to straight bridge to the examined value of $R=150 \mathrm{~m}$ ) induces enhancement of structural response for all bridges analysed in this study. Demand fragility curves, shown in Figure 4, confirm the above findings. These curves represent the conditional probability of exceeding a particular value of 0.02 for resultant CDR (P (EDP) $\mathrm{EDP}>$ resultant drift $=2 \%$ ), and they are constructed as a lognormal cumulative distribution function of responses based on previously determined coefficients $a, b$ and dispersion $\sigma$. The value of $2 \%$ for CDR $[22,23]$ represents a damage state in which a significant plastic behaviour is present in critical column cross sections, spalling of larger surfaces of the protective coat is present, widening and propagation of cracks is also visible, but the structure is still outside of the collapse zone and vertical elements are capable of sustaining vertical loads. According to [24] this level of CDR corresponds to the limit state of significant damage. 

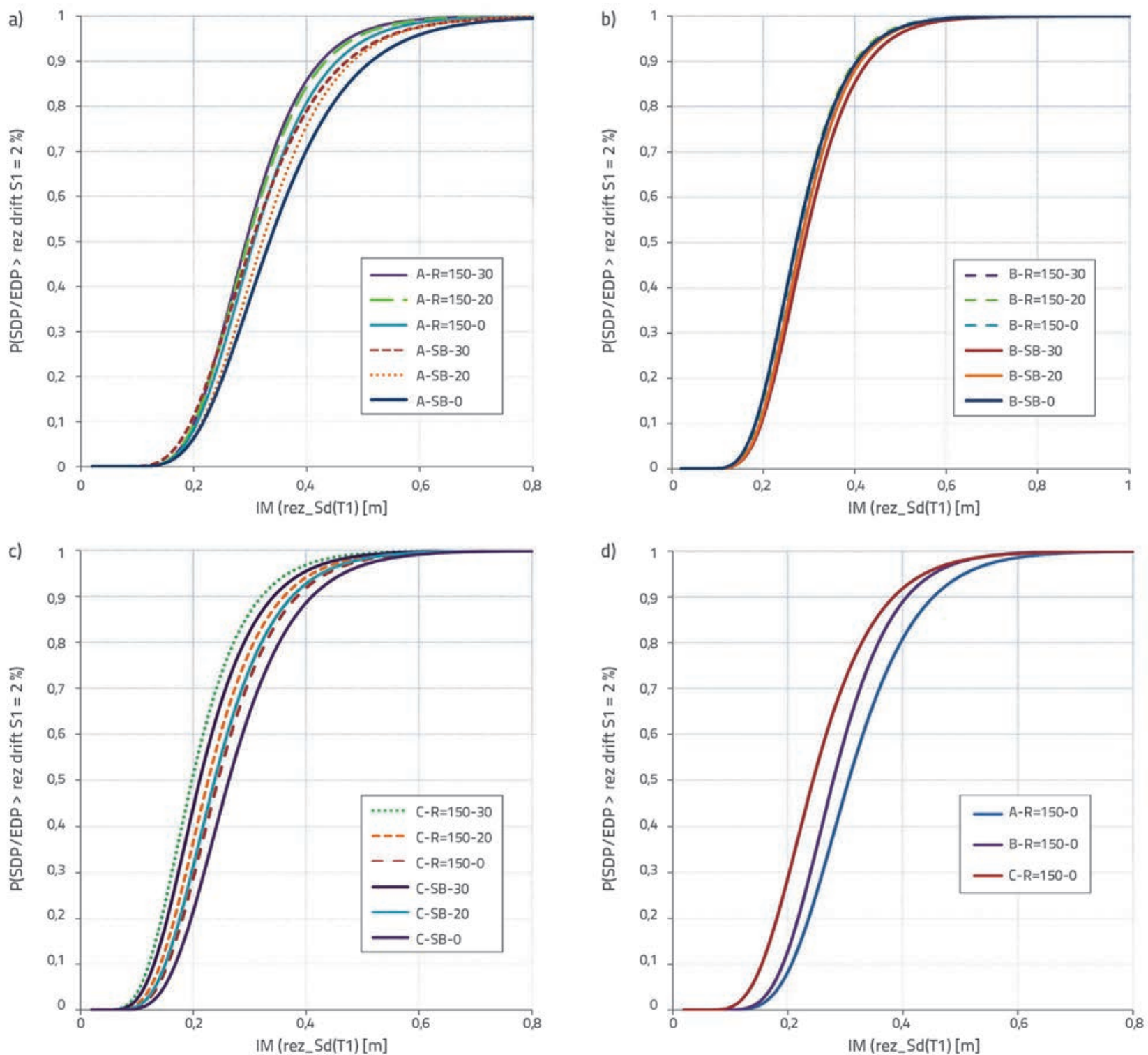

Figure 4. Demand fragility curves: a) bridge type $A$; b) bridge type $B ; c)$ bridge type $C$; d) comparing demand fragility curves for curved bridges $A$; $B$ and $C$ and skew angle of $0^{\circ}$

An increase in bridge sensitivity and conditional probability that CDR will exceed given value is noted as a decrease in the radius of bridge deck curvature. An increase in skew angle has a similar effect on bridge vulnerability, except for straight bridges of type $B$, where a not so pronounced but opposite trend was observed. This fact can be explained by slight increase of torsional stiffness with regard to the change in skewness, where smaller in plane deck rotations and consequently smaller column drifts are induced. This pattern has not been observed in curved bridges of type B, which are the least sensitive to change in skew angle. The greatest impact of varied parameters on structural response is observed in bridges with rectangular columns (type C). Generally, structural response of type $B$ bridges is the least affected by variation of examined parameters. Also, comparing curved bridges $A, B$ and $C$, it can be noted that bridges with rectangular wall-type columns have clearly been the most affected by variation of parameters.

\section{Conclusion}

The aim of this research is to assess the impact the bridge horizontal curvature and bent skew angle have on the seismic structural response, using the probabilistic seismic demand model. Eighteen bridge prototypes were analysed, with three types of column shapes, two radii of curvature, and three angles of skewness. The results of the analysis point to the following:

- Increase of bent skew angle causes shortening of longitudinal vibration mode periods and an increase in transverse vibration mode periods. Also, an increase in skewness leads to significant modal responses coupling between responses in two horizontal directions for bridges with double column bent, while for bridges with rectangular and hollow box column a contribution of rotational vibration modes becomes more pronounced; 
- Most efficient earthquake intensity measures are those that depend on structural characteristics, calculated from the resultant spectrum when combined with the resultant column drift ratio. The resulting spectrum is obtained as the vector sum of spectra of two horizontal components. When spectral intensity measures calculated in this way are used, a lower dispersion of results is obtained compared to the use of spectral measures calculated from component spectra only;

- Resultant spectral displacement for the fundamental mode period, calculated from the resultant spectrum, was found to be a good measure. This measure has a slightly higher dispersion value than the measure proposed by Cordova, but is considered more advantageous because of its simplicity;

- A decrease in the bridge deck horizontal curvature radius results in an increase in vulnerability response of the bridge;

- Bridges with a significant torsional mode contribution showed higher sensitivity to varied parameters. The bridge vulnerability increases with a decrease in radius and increase in skewness;

\section{REFERENCES}

[1] Priestley, M.N.J., Seible, F., Calvi, G.M.: Seismic design and retrofit of bridges, Wiley, NY,1996, https://doi.org/10.1002/9780470172858

[2] Tondini, N., Stojadinovic, B.: Probabilistic seismic demand model for curved reinforced concrete bridges, Bulletin of Earthquake Engineering, 10 (2012), pp.1455-1479, https://doi.org/10.1007/ s10518-012-9362-y

[3] Zakeri, B., Padgett, J., Ghodrati Amiri, G.: Fragility Assessment of Skewed Single-Frame Concrete Box Girder Bridges, ASCE Journal of Constructed Facilities, 28 (2014) 3, pp. 571-582.

[4] Kaviani, P., Zareian, F., Taciroglu, E.: Performance-Based Seismic Assessment of Skewed Bridges, Pacific Earthquake Engineering Research Center, PEER Report 2014/01, Berkeley, California, USA, 2014.

[5] Cornell, C.A., Krawinkler, H.: Progress and challenges in seismic performance assessment, Pacific Earthquake Engineering Research Center, PEER Center News, 3 (2000) 2, pp. 4

[6] EN 1991-2:2003, Action on structures-Part 2: Traffic loads on bridges

[7] EN 1992-1-1:2004, Eurocode 2: Design of concrete structures Part 1-1: General rules and rules for buildings

[8] EN 1998-2: 2005, Eurocode 8: Design of structures for earthquake resistance - Part 2: Bridges

[9] Computers and Structures, Inc., 2009. SAP 2000 Nonlinear, Version 14.0.0, Structural Analysis Program, Berkeley, CA.

[10] Avrim, A., Mackie, K., Stojadinović, B.: Guidelines for Nonlinear Analysis of Bridge Structures in California, Pacific Earthquake Engineering Research Center, PEER Report 2008/03, Berkeley, California, USA, 2008.

[11] SeismoSoft, 2014, SeismoStruct - v. 7.0.3 A computer Program for Static and Dynamic Non-linear Analysis of Framed Structures, Available from: http://www.seismosoft.com

[12] Mander, J.B., Priestley, M.J.N., Park, R.: Theoretical stress-strain model for confined concrete, Journal of Structural Engineering, 114 (1988) 8, pp. 1804-1826.

[13] Martinez-Rueda, J.E., Elnashai A.S.: Confined concrete model under cyclic load, Materials and Structures, 30 (1997) 197, pp. 139-147.
- An increase in bridge bent skewness leads to an increase in response, except for bridges with two column bent. Straight multi-column bridges even tend to behave in an opposite manner, which can be explained by enhancement of bridge torsional stiffness and, consequently, by lower column drifts. Curved multi-column bent bridges are the least sensitive to change in skew angle.

These results and conclusions are made based on the assumption of solid ground at the location, and for the case of neglected mass of abutments due to bridge length. The effects of soft soil, as well as the near fault earthquake effect, are not considered. Future studies should include these parameters. In addition, future research should focus on the bridge structures that are more flexible, and on those with higher columns, and should also include other values for bridge curvature radius. A detailed analysis of collapse should be done for these structures by defining the collapse criteria, i.e. by establishing the displacement ductility value or the column cross section curvature ductility at the beginning of the collapse limit state or other damage limit state.

[14] Caltrans: Seismic design criteria 1.4. California Department of Transportation, Sacramento, CA, 2006.

[15] Maroney, B.H., Chai, Y.H.: Seismic design and retrofitting of reinforced concrete bridges. Proceedings of $2^{\text {nd }}$ International Workshop, Earthquake Commission of New Zealand, Queenstown, New Zealand, 1994.

[16] Hwang, H., Liu, J.B., Chiu, Y.H.: Seismic Fragility Analysis of Highway Bridges, Report No. MAEC RR-4, Center for Earthquake Research Information, 2000.

[17] Choi, E., DesRoches, R., Nielson, B.: Seismic Fragility of Typical Bridges in Moderate Seismic Zones, Engineering Structures, 26 (2004) 2, pp.187-199.

[18] Mackie, K., Stojadinovic, B.: Seismic demands for performancebased design of bridges, Pacific Earthquake Engineering Research Center, PEER Report 2003/16, Berkeley, California, USA, 2003.

[19] Kramer, S.: Geotechnical Earthquake Engineering, Prentice-Hall International Series, 1996.

[20] Cordova, P.P., Deierlein, G.G., Mehanny, S.S.F., Cornel, C.A.: Development of two-parameter seismic intensity measure and probabilistic assessment procedure, The second US-Japan Workshop on Performance-Based Earthquake Engineering Methodology for Reinforcement Concrete Building Structures, Sapporo, Hokkaido, pp. 187-206, 2001.

[21] Pejović, J., Janković, S.: Dependence of RC high-rise buildings response on earthquake intensity, GRADEVINAR, 67 (2015) 8, pp. 749-759, https://doi.org/10.14256/JCE.1205.2014

[22] Yi, J., Kim, S., Kushiyama, S.: PDF interpolation technique for seismic fragility analysis of bridges, Engineering Structures, 29 (2007) 7, pp.1312-1322.

[23] Li, J., Spenser, B.Jr., Elnashai, A.: Bayesian Updating of Fragility Functions Using hybrid Simulations, Journal of Structural Engineering, 139 (2013) 7, pp. 1160-1171.

[24] EN 1998-3:2005, Design of structures for earthquake resistance Part 3: Assessment and retrofitting of buildings 